\title{
Kant e Aristóteles como paradigmas da ética normativa: uma separação intransponível?
}

\author{
Kant and Aristotle as paradigms of normative ethics: an \\ insurmountable separation?
}

Gustavo Françal

\begin{abstract}
RESUMO
Este artigo pretende traçar as linhas gerais de uma interpretação da ética de Immanuel Kant (1724-1804) que contraria a leitura mais difundida nos manuais e no debate acadêmico contemporâneo. Buscaremos expor os elementos da filosofia prática kantiana que lançam sérias dúvidas sobre a narrativa de que ela representaria um paradigma radicalmente oposto às éticas clássicas, particularmente a de Aristóteles (384 a. C. - 322 a. C.). Nessa esteira, iniciaremos apresentando um panorama geral da interpretação mais comum, que vê uma separação intransponível entre o mundo moral dos antigos e o dos modernos, dando particular atenção à visão chamada construtivista de John Rawls (1921-2002), profundamente influente nas discussões morais de nossos dias. Em seguida, traremos à baila três aspectos fundamentais da ética kantiana, que permitem fundamentar a tese daqueles que desafiam o esquema ordinário: i) a doutrina do factum da razão; ii) a importância central da fórmula da humanidade do imperativo categórico; e iii) as obras de ética material de Kant, em que aparece a aplicação da lei moral na dedução de deveres concretos.
\end{abstract}

PALAVRAS-CHAVE: Ética, Kant, Aristóteles, construtivismo, realismo, deontologia, teleologia, lei moral, fins, felicidade.

\begin{abstract}
This article intends to trace the general lines of an interpretation of the ethics of Immanuel Kant (1724-1804) that contradicts the more widespread reading in the manuals and in the contemporary academic debate. We will seek to expose elements of Kantian practical philosophy that cast serious doubts on the narrative that it would represent a paradigm radically opposed to classical ethics, particularly that of Aristotle (384 BC. - 322 BC.). In this context, we will begin by presenting an overview of the most common interpretation, which sees an insurmountable separation between the moral world of the ancients and that of the moderns, paying particular attention to the so-called constructivist view of John Rawls (1921-2002), deeply influential in moral discussions of our day. Then, we will bring up three fundamental aspects of Kantian ethics, which make it possible to substantiate the thesis of those who challenge the ordinary scheme: i) the doctrine of the factum of reason; ii) the central importance of the formula of humanity of the categorical imperative; and iii) the works of material ethics by Kant, in which appears the application of the moral law in the deduction of concrete duties.
\end{abstract}

\footnotetext{
${ }^{1}$ Doutorando em Filosofia pela Universidad de Navarra. Mestre em Filosofia pelo IFCS da UFRJ.
} 
KEYWORDS: Ethics, Kant, Aristotle, constructivism, realism, deontology, teleology, moral law, ends, happiness.

\section{INTRODUÇÃO}

O escopo do presente artigo é apresentar os contornos gerais de uma interpretação particular da ética de Immanuel Kant (1724-1804). O objetivo de tal interpretação é desafiar a leitura mais consagrada, que a rotula como a representação arquetípica das éticas modernas, em oposição quase simétrica às éticas clássicas, que teriam em Aristóteles (384 a. C. - 322 a. C.) seu patrono por excelência.

Desse modo, no primeiro tópico do desenvolvimento deste trabalho, traçarei um brevíssimo panorama dessa leitura mais vulgar da ética kantiana, presente, em geral, nos manuais filosóficos. Mostraremos como a noção de que existe um mundo moral dos modernos - formalista, legalista, deontológico, logicista, alheio a bens e a fins, que trata a felicidade e os desejos pessoais como meramente subjetivos - inimigo em tudo da cosmovisão ética dos antigos, substancial, comunitária, teleológica, fundada em bens e em fins, perfeccionista, eudemonista - e de que Kant e Aristóteles são os representantes por antonomásia de ambas as concepções é compartilhada por autores tão distintos entre si quanto Henry Sidgwick, Elizabeth Anscombe, William Frankena e C. D. Broad.

Além disso, daremos destaque à apropriação kantiana de John Rawls (1921-2002), que, por ser o autor mais influente no debate moral e político dos últimos anos, adquiriu particular eco, sendo vista em muitos meios como a principal atualização do kantismo para as disputas teóricas contemporâneas. Explicaremos que Rawls tem uma leitura bastante peculiar de Kant, que nomeia de construtivismo e que coloca o filósofo prussiano em confronto radical com a cosmovisão clássica no campo da metafísica.

Delineada a leitura mais tradicional, passaremos a explorar a interpretação oposta, que será defendida aqui. Dividiremos nossa exposição em três elementos fundamentais da obra kantiana, que, segundo creio, nos revelam uma visão da ética desse filósofo bem diferente daquela a que nos acostumamos. 
Em primeiro lugar, exporemos a doutrina kantiana do factum da razão. A ideia é demonstrar que não há fundamento para supor que, em Kant, as normas morais sejam construídas pela razão. Pelo contrário, a lei moral é um dado numênico da realidade, uma parte da constituição racional da natureza humana. A concepção de Kant a respeito do estatuto metafísico da lei moral é bastante próxima do realismo clássico.

Em seguida, daremos lugar à tese de que, ao contrário do enfoque normalmente dado pelos intérpretes, que creem que a primeira fórmula do imperativo categórico (a fórmula da lei universal) é o resumo da moralidade kantiana, a segunda fórmula (a fórmula da humanidade) é a que ocupa um lugar central no pensamento ético do nosso filósofo. Quando Kant aplica a lei moral para deduzir os deveres concretos, em suas obras de ética material, é sempre a fórmula da humanidade que ele utiliza. A centralidade dessa formulação tem implicações para uma teoria da ação e do seu ajuizamento moral - ela revela que toda a estrutura da ação humana, tanto descritiva quanto normativa, em Kant, é essencialmente teleológica. A deontologia kantiana, de modo algum, é alheia a um sistema de fins.

Por último, no quinto tópico deste trabalho, apresentaremos alguns traços gerais das obras de ética material de Kant, notadamente "A metafísica dos costumes" e as "Lições de ética". Tais obras costumam ser relegadas a um segundo plano na análise do iluminista de Königsberg, restringindo-se seus comentadores a ler a "Fundamentação da metafísica dos costumes" e a "Crítica da razão prática". Tentaremos esclarecer que o recurso a tais obras permite destruir de vez a ideia de um Kant formalista e abstracionista. Vemos aqui um Kant fortemente cuidadoso com a antropologia e buscamos adaptar a lei moral à realidade concreta dos seres humanas. Veremos, ainda, nessa linha, que Kant não despreza os sentimentos, nem a felicidade, e que a eudaimonia aristotélica corresponde ao que Kant chama de sumo bem, o bem humano integral (a conjunção estável entre a plena virtude e a plena felicidade), que é a aspiração inata da razão prática pura.

Como é óbvio, nenhum desses temas pode ser totalmente desenvolvido num artigo como este. Meu objetivo aqui não é, de maneira nenhuma, esgotar as questões agora levantadas, nem proporcionar uma defesa definitiva da postura proposta. Trata-se, simplesmente, de uma apresentação inicial dos temas centrais da ética kantiana que vêm sendo invocados por muitos respeitáveis comentadores como motivos sólidos para se rechaçar o esquema mais tradicional. 


\section{A INTERPRETAÇÃO FORMALISTA DE KANT}

Está mais do que consagrado nos manuais de Ética a divisão do pensamento moral em duas eras estanques e radicalmente opostas: as éticas clássicas e as éticas modernas. Cada uma delas representaria, nessa leitura, um paradigma fundamentalmente distinto de investigação acerca das questões morais e de sua formulação, havendo entre esses paradigmas um abismo a separar dois mundos incomensuráveis. Não raro, Aristóteles e Kant costumam ser apresentados como os dois representantes arquetípicos de cada um dos modelos de teoria moral.

Nos termos dessa narrativa tradicional, os antigos centrariam sua ideia de moralidade no bem, no bem objetivo, encontradiço na realidade e identificável a partir dos fins naturais do ser humano. As éticas antigas são, sobretudo, teleológicas. O homem educa as suas inclinações por meio das virtudes, e a ação correta é sempre fruto de uma ponderação prudencial das circunstâncias, nunca de regras universais abstratas. As virtudes humanas são gestadas no âmbito da comunidade e sempre levam em conta a cultura e as tradições.

O ponto de transformação teria sido a ascensão do cristianismo, que poria no centro da vida moral um conjunto de leis e de regras, vistas como mandamentos divinos. Com a fratura da cristandade, na Reforma Protestante, a filosofia moral moderna passou a ter como tarefa encontrar um fundamento para justificar a ação correta que pudesse ser visto como válido por indivíduos de distintos credos religiosos e metafísicos. Assim, as éticas modernas se baseiam em leis universalmente vigentes, mas despidas de seu fundamento teológico medieval.

Tais éticas têm a norma e o dever como seus conceitos fulcrais. Elas são deontológicas e universalistas. A ação correta vem de uma prescrição que vale absolutamente, independentemente das circunstâncias, e pode ser identificada pela razão, sem qualquer conexão com sociedades, culturais, tradições ou religiões particulares ${ }^{2}$.

\footnotetext{
${ }^{2}$ Cf. ENGSTROM, Stephen e WHITING, Jennifer, Introduction. In: ENGSTROM, Stephen e WHITING, Jennifer (eds.). Aristotle, Kant, and the Stoics: Rethinking Happiness and Duty. Cambridge: Cambridge University Press, 1996, pp. 1-2.
} 
Essa mesma narrativa pode ser encontrada em autores tão díspares quanto Henry Sidgwick $^{3}$ e Elizabeth Anscombe ${ }^{4}$. Quase todos os manuais recentes de ética são perpassados por essa visão, e defensores de uma ou de outra tradição costumam concordar em tomar por assentada essa separação radical entre os dois mundos morais.

Nessa linha explicativa, Kant é sempre representado como um pensador formalista ao extremo, proponente de um procedimento racional que não é mais do que um teste vazio para máximas subjetivas, sem nenhum compromissos com valores substanciais, mas apto simplesmente a delinear, com poucos critérios lógicos, o mínimo racionalmente necessário para a convivência de pessoas com distintas ideias do bem. Trata-se de uma ética rigorista, que despreza as circunstâncias em sua pretensão de validade universal, que não leva em conta a natureza humana, os sentimentos ou a felicidade.

Esses manuais costumam ser influenciados pela distinção terminológica que entrou para a história da Filosofia pela pena de David Ross (1877-1971), em sua famosa obra "The Right and the Good" ". Ali, Ross estabeleceu uma distinção entre o bem e o certo, ou o justo. Essa distinção, muitas vezes, aparece no centro da separação que se interpõe entre o modo clássico e o modo moderno de pensar a moral.

A imagem de Kant agora descrita pode ser encontrada, a título de breves exemplos, em C. D. Broad ${ }^{6}$ e em William Frankena ${ }^{7}$. Em ambos, a constatação é de que Kant inverteu os termos da ética antiga, pondo o certo como conceito central, sendo o bem e o mal definido a partir dele. Quer dizer, é a lei moral, derivada de uma vontade racional pura, que dita aquilo que pode ser considerado bom ou mal.

Tais comentadores reduzem o imperativo categórico a um teste lógico vazio, universalmente aplicável a todos os seres humanos a todas as suas ações, independentemente de suas circunstâncias, de seus desejos e apetites particulares. A primeira fórmula do imperativo (a fórmula da lei universal) seja o princípio formal suficiente para derivar todas as obrigações

\footnotetext{
${ }^{3}$ Cf. SIDGWICK, Henry. Outlines of the History of Ethics for English Readers. London: Macmillan and Co., $6^{\mathrm{a}}$ ed., 1931, pp. 6-7.

${ }^{4}$ Cf. ANSCOMBE, G. E. M.. Modern Moral Philosophy. In: The Collected Philosophical Papers of G. E. M. Anscombe, vol. III: Ethics, Religion and Politcs, Oxford: Basil Blackwell, 1981, pp. 26-42.

${ }^{5}$ Cf. ROSS, David. The Right and the Good. Ed. rev., ed. Phillip Stratton-Lake, Oxford: Clarendon Press, 2002.

${ }^{6}$ Cf. BROAD, C. D.. Five Types of Ethical Theory. Londron: Routledge \& Kegan Paul, 1930, pp. 116-120.

${ }^{7}$ Cf. FRANKENA, William. Ethics. $2^{\text {a }}$ ed. Englewood Cliffs: Prentice Hall, 1973, pp. 30-31.
} 
morais, e os quatro famosos exemplos da "Fundamentação da metafísica dos costumes" seriam a demonstração definitiva do modo de aplicar o imperativo.

Com base nisso, esses comentadores costumam criticar Kant, entendendo ser evidente que a ação correta, muitas vezes, não pode ser definida numa abstração universal, mas depende das circunstâncias concretas do agente e da natureza da situação em que se encontra. Além disso, é extremamente questionável que, de fato, o simples conceito de natureza racional permita deduzir critérios claros para o imperativo categórico ${ }^{8}$.

Põe-se ainda em cheque o rigorismo kantiano, com sua noção de que regras aprovadas em abstrato devem se tornar universais e aplicáveis a todas as ocasiões, não deixando espaço para flexibilizações e exceções. Frankena também objeta que máximas banais e inteiramente neutras podem facilmente ser aprovadas pelo filtro do imperativo categórico, tornando-se, assim obrigatórias (como "assobiar sempre que esteja sozinho no escuro" ou "amarrar sempre primeiro o cadarço do sapato esquerdo") $)^{9}$.

Essa interpretação formalista de Kant adquire uma particular influência no debate contemporâneo com a obra de John Rawls (1921-2002). Rawls, por um lado, é o proponente de uma teoria moral e política original que costuma ser vista como herdeira do kantismo na arena intelectual contemporânea. Por outro, é ele próprio um comentador de Kant, tendo dedicado ao filósofo de Königsberg dez conferências de sua "História da filosofia moral"10.

Como a obra de Rawls "Uma teoria da justiça" marcou definitivamente todo o debate ético depois de si, fazendo-se ponto de partida de todos os que se manifestam no âmbito da teoria da justiça, seja para aderir a ela, seja para a ela se opor (esse fato é reconhecido mesmo por alguns de seus mais atrozes adversários), a visão de Kant nos nossos dias está fortemente vinculada à interpretação realizada por Rawls. Tal interpretação, como veremos, apresenta um desenvolvimento peculiar da leitura formalista consagrada.

\footnotetext{
${ }^{8}$ Cf. BROAD, op. cit., pp. 124-128.

${ }^{9}$ Cf. FRANKENA, op. cit., pp. 32-33.

${ }^{10}$ RAWLS, John. História da filosofia moral. Org. Barbara Herman, trad. Ana Aguiar Cotrim, rev. da trad. Marcelo Brandão Cipolla. - São Paulo, Martins Fontes, 2005, pp. 165-372.

${ }^{11}$ Id. Uma teoria da justiça. Trad. Jussara Simões, rev. téc. Álvaro de Vita. - $3^{\mathrm{a}}$ ed. - São Paulo: Martins Fontes, 2008.
} 
A leitura que Rawls opera de Kant, com efeito, está vivamente marcada pelas chaves interpretativas que antes descrevemos. Rawls desenha um Kant filiado a um procedimentalismo moral estrito, em que não existem fatos morais autoevidentes. A lei moral só pode ser identificada por um procedimento correto vazio, que não supõe nada de material, mas parte exclusivamente de uma definição formal das faculdades morais humanas ${ }^{12}$.

O imperativo categórico, apresentado sempre na fórmula da lei universal, seria esse filtro vazio, apto a testar as diversas máximas particulares, a fim de verificar sua compatibilidade com a razão prática. Rawls descreve o "procedimento do imperativo categórico" como a sequência de alguns passos lógico e entende que esse seria o verdadeiro resumo da ética kantiana, em seu pleno vigor.

Rawls acredita que, em Kant, a validade universal das normas morais se extrai do fato de que foram aprovadas por esse procedimento correto. $\mathrm{O}$ procedimento do imperativo categórico traria em si as exigências que nossa razão prática impõe às nossas ações. Nossas máximas serão morais simplesmente se forem aprovadas por esse procedimento. A totalidade da doutrina ética não é mais do que o conjunto de leis resultantes da aplicação universal do imperativo categórico. Tais normas adquirem legitimidade universal exatamente porque estão fundadas apenas numa noção formal da natureza humana racional, sem qualquer vínculo com ideias particulares de bem, ou com noções culturais de felicidade ou de excelência ${ }^{13}$.

Rawls, entretanto, leva a leitura formalista um ponto mais adiante, ao introduzir sua proposta de classificação da ética kantiana, que batiza de construtivismo ético.

Rawls apresenta o construtivismo com uma observação interessante: para ele, é fundamental perceber que Kant se opõe não somente ao utilitarismo, mas também ao chamado intuicionismo racional. O professor de Harvard lamenta que a rejeição de Kant a este último (na versão do perfeccionismo de Gottfried Leibniz (1646-1716)) não tenha recebido tanta atenção dos críticos quanto aquela dirigida às éticas utilitaristas e naturalistas. A verdade,

\footnotetext{
${ }^{12}$ Cf. id., ibid., pp. 51; 104-105. Também id., Kantian Constructivism in Moral Theory. In: id. Collected Papers. Ed. Samuel Freeman. Cambridge: Harvard University Press, 1999, pp. 310-311; 333-334.

${ }^{13}$ Cf. id., História da filosofia moral..., pp. 193 e ss..
} 
porém, seria que também o intuicionismo racional é claramente considerado como heterônomo ${ }^{14}$.

No intuicionismo racional, os princípios morais são sintéticos a priori e, portanto, independentes de toda a ordem da natureza. São conhecidos exclusivamente pela razão, com total independência de fatores empíricos que poderiam induzi-la. $\mathrm{O}$ fato de que Kant atribui heteronomia também a esse modelo de pensamento significa que, para que uma moral seja autônoma, não basta que ela reconheça uma ordem de fatos a priori externa a ela, puramente inteligíveis e fora do alcance das contingências fenomênicas. Há heteronomia sempre que os princípios morais sejam fundados em relações entre objetos não determinados por nossa concepção de nós mesmos como seres dotados de razão prática pura. O construtivismo kantiano exige que não exista nenhuma ordem moral anterior às autoconcepções formais que originam o procedimento racional correto ${ }^{15}$.

Desse modo, o cerne do construtivismo moral é que, nele, as leis morais são produzidas pelo procedimento do imperativo categórico, que é um simples reflexo das nossas faculdades morais formais. Quer dizer, não é apenas que a moralidade se defina como aquilo que pode ser aprovado pelo procedimento racional adequado, mas que é esse mesmo procedimento que cria as normas morais. Não há fatos morais anteriores a ele.

Portanto, ocorre aqui uma inversão do intuicionismo racional. Não existe uma ordem de valores a priori na realidade, que seja captada pela razão prática. Nada há que seja anterior ao procedimento racional do imperativo categórico. A ordem dos valores é construída por esse mesmo procedimento. Se, no intuicionismo racional, o procedimento é considero correto porque com ele é possível chegar à ordem de valores verdadeira, no construtivismo o resultado moral é correto apenas porque advém do procedimento adequadamente estabelecido pelo funcionamento da razão prática ${ }^{16}$.

Ou seja, a proposta construtivista de Rawls invade o campo das disputas metafísicas, ao adquirir um marcante traço antirrealista. Não existe nenhum “dado moral” na realidade. Não há fatos morais, naturais ou sequer meramente inteligíveis, anteriores ao procedimento de

\footnotetext{
${ }^{14}$ Cf. id., ibid., p. 270.

${ }^{15}$ Cf. id., ibid., pp. 271-272.

${ }^{16}$ Cf. id., ibid., pp. 275-278.
} 
construção. Os valores morais são uma criação humana. É a razão humana que os produz, para serem não "verdadeiros" segundo uma correspondência a uma realidade natural dada, mas simplesmente adequados à nossa constituição racional.

Fizemos, aqui, um brevíssimo esboço dos contornos gerais da interpretação mais em voga da ética kantiana. Nos tópicos seguintes, buscarei explicitar os motivos pelo quais essa leitura me parece equivocada. Veremos três aspectos nucleares do pensamento moral de Kant, que, a meu ver, revelam um distanciamento substancial em relação à imagem que mais comumente se faz dele.

\section{A LEI MORAL COMO UM FACTUM DA RAZÃO}

O ponto de partida para uma compreensão correta da ética kantiana é debruçar-se sobre como nosso filósofo entende a própria realidade da lei moral. Ele dedica a esse tema a seminal Terceira Seção da "Fundamentação da metafísica dos costumes" e retomará o ali esclarecido mais adiante, na "Crítica da razão prática".

A última seção da "Fundamentação", alvo de infindáveis debates e compreensões truncadas, trata justamente da liberdade e de suas consequências para a apreensão do mundo à nossa volta. Depois de demonstrar, passo-a-passo, o que significa atuar segundo uma vontade puramente racional e como isso nos leva aos fundamentos dos nossos deveres morais, Kant se depara com o corolário dessa concepção que ele acaba de descrever: a noção de liberdade.

Quer dizer, se temos a capacidade de agir segundo uma determinação puramente interior da razão prática, isso significa que somos dotados de liberdade, de uma causalidade para as nossas ações totalmente independente das causalidades mecânicas, que vem diretamente de nossa consciência e determina, por si mesma, de modo radicalmente originário, uma ação. Uma 
vontade livre é uma vontade capaz de agir segundo leis que não são as leis da necessidade fenomênica, mas leis dadas pela própria razão ${ }^{17}$.

Se a ideia de liberdade está muito bem estabelecida, Kant se pergunta como podemos provar a sua realidade. Ao que parece, nossa percepção teórica apenas nos fornece uma causalidade totalmente mecânica, própria do mundo da ciência física. A sucessão mecânica de causas que constatamos empiricamente no mundo dos fenômenos não aparenta deixar espaço para a causa eficiente da liberdade.

A solução de Kant para isso é cruamente singela: como sabemos, nosso conhecimento teórico penetra apenas uma parte da realidade, que é o que Kant denomina fenômenos, aquilo que aparece às nossas faculdades cognitivas. O mundo inteligível é formado por aquilo que está mais além do que pode ser empiricamente captado pela cognição humana e que, consequentemente, é em si mesmo.

Se é verdade que o ser humano pertence ao mundo sensível, ele, como todos os seres racionais, é também inteligível. A razão prática é justamente a sua faculdade puramente intelectual, externa ao mundo sensível e que o comanda desde fora. A liberdade é, assim, um fato metafísico. Trata-se de uma causalidade numênica, que produz efeitos desde fora da realidade empírica.

A liberdade, portanto, não pode ser demonstrada. Ela não é um fato empírico, que possa ser visto ao microscópio. Ela não está em contradição com a cadeia fechada da causalidade mecânica porque ela atua em outro plano da realidade. Os homens, desde o ponto de vista sensível, estão submetidos às leis físicas da natureza, mas, desde o ponto de vista inteligível, estão submetidos à lei da liberdade, à lei da razão prática pura.

Conhecemos a realidade da lei moral e da liberdade por uma autoexperiência inescapável. Percebemos em nós mesmos que somos dotados de inteligência e de autoconsciência. Só consigo representar nossas próprias ações pressupondo a ideia de liberdade. É impossível ao homem atuar senão pressupondo que é livre. Esse é um fato básico e irrefutável da experiência humana na terra. Até para argumentar contra a existência da liberdade, é

\footnotetext{
${ }^{17}$ Cf. KANT, Immanuel. Fundamentação da metafísica dos costumes. Trad., int. e notas Guido Antônio de Almeida. - São Paulo: Discurso Editorial: Barcarolla, 2009, pp. 347-351.
} 
necessário pressupor nossa liberdade de fazê-lo e a liberdade do interlocutor de acatar nosso $\operatorname{argumento}^{18}$.

Trata-se da doutrina do factum da razão, que Kant desenvolve na "Crítica da razão prática". A lei moral se dá imediatamente a nós, como uma autoexperiência ineliminável de que somos capazes de agir e de emitir juízos segundo uma causalidade absolutamente independente das necessidades empíricas dos impulsos e dos apetites.

Temos uma consciência imediata de que a lei moral atua dentro de nós. Essa consciência da lei moral não é um fato empírico, mas um factum puramente inteligível, uma constatação racional, de que a razão se manifesta no âmbito prático. A consciência da lei moral nos leva a conhecer, com segurança, a realidade da liberdade, que se afigura como a própria capacidade de a razão prática pura ser eficiente ${ }^{19}$.

A percepção intelectual do factum da razão se mostra com bastante clareza quando examinamos nossos próprios juízos práticos cotidianos. É fácil perceber que, numa variedade de situações, julgamos algo justo ou injusto independentemente da satisfação de nossos desejos materiais. Kant figura o exemplo de um homem a quem, prestes a ser condenado à morte, lhe é oferecido acusar um inocente e, assim, salvar a própria vida. Nessa circunstância, consideramos imediatamente que o homem tem o dever de não fazer o que lhe é proposto e que, caso o faça, age de maneira brutalmente injusta, ainda que não lhe sobrevenha nenhuma vantagem em agir assim, mas totalmente ao contrário. Isso porque nossa consciência moral é afetada por uma lei que vem de fora do mundo dos sentimentos e das inclinações, da própria razão ${ }^{20}$.

Portanto, aqui, acontece o contrário do que se verifica na teoria do conhecimento de Kant, âmbito no qual talvez, em algum sentido, se possa falar em construção, na medida em que o conhecimento é resultado de um processo de aplicação das categorias do entendimentos aos dados vindos da sensibilidade. Na ética, ao contrário, não se constrói nada. A lei moral é um dado. Ela se apresenta imediatamente como o númeno da razão prática pura. Aqui, inversamente do que acredita Rawls, não há construtivismo, mas efetivo realismo.

\footnotetext{
${ }^{18}$ Cf. id., ibid., pp. 361-373.

${ }^{19}$ Cf. Id., Crítica da razão prática. Trad., int. e notas Valerio Rohden. - São Paulo: Editora WMF Martins Fontes, $3^{\mathrm{a}}$ ed., 2011, pp. 49-51.

${ }^{20}$ Cf. id., ibid., pp. 53-55.
} 
Na explicação de Karl Ameriks, é verdade que o fundamento central da ética kantiana é que a moral vem da razão. Essa tese, entretanto, pode ser interpretada de duas formas, usando os termos da metafísica clássica: i) a razão é causa eficiente da lei moral, isto é, a razão faz a moral, fabrica o conteúdo dos imperativos práticos; ou ii) a razão é causa formal da lei moral, isto é, a moralidade é a própria essência da razão humana, constitutiva de sua natureza abstrata e geral.

A primeira interpretação é a construtivista. Entretanto, o discurso de Kant a respeito da consciência da lei moral e do factum da razão nos mostram que devemos entender seu racionalismo no segundo sentido. A razão não cria a moral, ela a reconhece. A própria natureza da razão prática, por si, contém os fins últimos a que se dirige e que devem guiar a ação humana (explicaremos isso em mais detalhes no tópico seguinte). Os comandos da razão ao indivíduo concreto expressam a natureza humana em seu estado mais elevado ${ }^{21}$.

Podemos dizer que, em Kant, a lei moral é o modo de ser da razão. Com isso, opomonos francamente ao título comumente atribuído de "ética do dever" ou, pior ainda, de "ética do dever pelo dever". Em Kant, não existe a separação humiana entre ser e dever-ser. A lei moral não é, por natureza, um dever.

A lei moral é um fato da realidade, é o ser prático da razão, é o modo de atuar próprios dos seres racionais. No caso dos homens, que são seres racionais finitos, que também pertencem ao mundo fenomênico, e que, por conseguinte, têm a possibilidade de não agir conforme a razão, ela assume a aparência de dever. A lei moral não é, em si, dever, mas tem, para nós, forma de dever porque nós temos a capacidade de obrar contrariamente o que nos mostra a razão.

Deus também possui a lei moral, mas não possui dever. Deus age bem por Sua própria natureza. Ele não tem a possibilidade de não agir bem. A moral é, para Ele, simples descrição de Seu comportamento. No caso dos seres racionais finitos, cuja natureza limitada e defectível comporta a possibilidade de agir mal, a moralidade deve assumir um caráter normativo e não descritivo. Em suma, para Kant, o ser da razão pura assume a forma de dever-ser quando

\footnotetext{
${ }^{21}$ Cf. AMERIKS, Karl. Interpreting Kant's Critiques. Oxford: Oxford University Press, 2003, pp. 278-280.
} 
contrastado com o ser fenomênico e empírico, dotado também de apetites e de desejos sensíveis ${ }^{22}$.

Podemos ver, assim, que o esquema geral da ética kantiana é bastante semelhante ao das éticas realistas clássicas. Alasdair MacIntyre afirma que as éticas clássicas, com suas distintas variantes, se centram numa estrutura tripartite, que articula: i) a natureza humana como ela é atualmente (fenomenicamente); ii) a natureza humana como ela deve ser, se realizar todas as suas potências; e iii) um conjunto de regras que mediam a passagem de um estado a outro ${ }^{23}$.

A ética kantiana funciona exatamente nesses mesmos termos. Há a natureza humana sensível, de como cada indivíduo é atualmente, com seus desejos e inclinações concretas, em suas circunstâncias concretas. E há a natureza humana racional, conforme a razão mostra que o homem deve chegar a ser, se realizar plenamente a sua humanidade. A lei moral é a chave que opera a passagem do estado atual para a perfeição racional. Vemos, aqui, que estamos já bastante distantes da imagem consagrada do Kant proponente de uma "deontologia formal" ou de um "rigorismo do dever pelo dever".

\section{A CENTRALIDADE DA SEGUNDA FÓRMULA DO IMPERATIVO CATEGÓRICO}

Um elemento fundamental que se pode observar em praticamente todos os comentadores de Kant que propõem a leitura tradicional é que sua análise do imperativo categórico está sempre centrada exclusivamente na primeira formulação, a fórmula da lei universal ("age segundo uma máxima tal que possas ao mesmo tempo querer que se torne uma lei universal"). Essa fórmula é apresentada, isoladamente, como o único e verdadeiro critério apresentado por Kant para determinar a moralidade.

Como sabemos, Kant, na "Fundamentação", em sua exposição do imperativo categórico, apresenta seus famosos quatro exemplos, nos quais mostra a aplicação da lei moral

\footnotetext{
${ }^{22}$ Cf. KANT, Crítica da razão prática..., pp. 132-133.

${ }^{23}$ Cf. MACINTYRE, Alasdair. Depois da virtude: um estudo em teoria moral. Trad. Jussara Simões, rev. téc. Hélder Buenos Aires de Carvalho. - Bauru, SP: Edusc, 2001, pp. 99-100.
} 
a situações concretas. Normalmente, os autores que citamos no tópico 2 consideram esses quatro exemplos o resumo definitivo e a totalidade mesmo da doutrina ética do pensador alemão.

Assim, é fácil perceber como o imperativo categórico fica reduzido a um filtro lógico para o teste de máximas particulares, a fim de verificar se podem ser harmonizadas com a convivência entre pessoas diferentes. A moral kantiana seria esse mínimo exigível universalmente, de modo que os fins particulares e as ideias de bem de cada um, numa sociedade cosmopolita e plural, possam coexistir pacificamente.

Com efeito, Rawls afirma explicitamente que, embora Kant escreva que as distintas formulações do imperativo categórico são equivalentes, tal afirmação não se sustenta, e a única fórmula realmente importante é a primeira. As demais não são capazes de alterar seu sentido nem de lhe acrescentar nada relevante ${ }^{24}$.

Rawls não vê problema em contradizer diretamente uma afirmação central de Kant, mas ele próprio se depara com a dificuldade criada por sua leitura. Ao explicar a aplicação do imperativo categórico aos quatro exemplos, ele admite que o raciocínio de Kant não é de todo compreensível e que a solidez do procedimento criado pelo filósofo prussiano permanece levantando muitas dúvidas.

O professor americano descarta dois dos quatro exemplos (do suicídio e do homem que se recusa a desenvolver suas habilidades), por considera-los "implausíveis". Além disso, mesmo nos dois exemplos restantes de que se utiliza em sua explicação, ele julga muito difícil compreender por que um homem racional "não pode querer" uma lei universal que admita a promessa enganosa ou o egoísmo. Por isso, termina por defender ser necessário acrescentar suposições alheias às teorias de Kant para esclarecer o seu raciocínio ${ }^{25}$.

Quer dizer, Rawls decepa a meditação de Kant de vários de seus elementos, e não lhe ocorre, em momento algum, que seja esse o motivo pelo qual o raciocínio kantiano se tornou um tanto gratuito e de difícil justificação.

\footnotetext{
${ }^{24}$ Cf. RAWLS, História da filosofia moral..., pp. 211-212.

${ }^{25}$ Cf. id., ibid., pp. 211-212.
} 
De fato, quando vamos às obras de ética material de Kant (a "Doutrina da virtude", segundo livro d"“A metafísica dos costumes" e as "Lições de éticas"), constatamos que, quando vai aplicar o imperativo categórico para deduzir deveres concretos, ele se vale quase exclusivamente da segunda fórmula do imperativo categórico, a fórmula da humanidade ("age segundo uma máxima tal que trates a humanidade, quer na tua pessoa, quer na de outrem, ao mesmo tempo como fim em si mesmo e não meramente como meio"), não a primeira.

Se a fórmula da lei universal explicita elegantemente num princípio formal a essência da moralidade, é a fórmula da humanidade a mais adequada para discernir o que deve ser feito em circunstâncias concretas. Ao contrário do que pensam os intérpretes procedimentalistas, os quatro exemplos da "Fundamentação" servem apenas para mostrar que o princípio deduzido em abstrato pode ser aplicado para resolver casos reais; não são o modo de aplicação desenvolvido por Kant para a sua teoria ética ${ }^{26}$. Para conhecer como a lei moral se aplica concretamente e quais são os deveres específicos do homem, é preciso recorrer às citadas obras de ética material, consoante explicaremos no próximo ponto deste artigo.

A proposição de Kant de que todas as formulações do imperativo categórico expressam a mesma coisa não pode ser simplesmente ignorada, como faz Rawls. Kant tem uma compreensão bem substancial e rigorosa do que uma vontade racional "pode querer" que seja uma lei universal. É o que demonstra a fórmula da humanidade: o que pode ser querido por um ser racional é o que trata a humanidade como um fim em si mesmo.

Quando se compreende que a fórmula da humanidade tem uma importância fundamental na demonstração do conteúdo concreto da lei moral, somos levados a dar-nos conta de algumas consequências de muito vulto, que exsurgem de uma leitura atenta de tal formulação.

A primeira é que ela supõe uma teoria da ação subjacente ${ }^{27}$. E tal teoria da ação é, ao contrário do que supõe a opinião mais consagrada, marcadamente teleológica. A tese de que Kant abandona toda e qualquer teleologia em sua filosofia prática não resiste sequer a uma leitura rápida da "Fundamentação".

\footnotetext{
${ }^{26}$ Cf. WOOD, Allen W. Kant. Trad. Delamar José Volpato Dutra. - Porto Alegre: Artmed, 2008, pp. 167-169.

${ }^{27}$ Para uma boa e cuidadosa análise da teoria da ação em Kant, ver DE HARO ROMO, Vicente. Duty, Virtue and Practical Reason in Kant's Metaphysics of Morals. Trad. Erik Norvelle. Hildesheim/Zurich/New York, OLMS, 2015, pp. 21 e ss.
} 
Em Kant, toda a ação tem um fim. Mais do que isso, tal característica é a definição mesmo da racionalidade. $\mathrm{O}$ que caracteriza a inteligência racional e a diferencia do arbítrio bruto dos animais é justamente a capacidade de definir fins para si próprio. O homem jamais pode agir por impulso bruto, mas sempre precisa internalizar racionalmente um princípio para guiar sua ação. Mesmo o homem que queira agir executando todos os seus desejos e apetites, ao fazê-lo, define conscientemente para si a finalidade de satisfazer suas inclinações e desobedecer à razão ${ }^{28}$.

No pensamento kantiano, além disso, o fim é o elemento central de definição de uma ação. Prestando-se atenção à formulação do imperativo categórico, vê-se que a ética lida não com ações, mas com máximas (“age segundo uma máxima tal...”). A máxima é o princípio subjetivo que guia a ação, eleito pelo indivíduo e que dirige a sua vontade a um fim real.

Ações exteriormente muito distintas podem estar fundadas na mesma máxima. Um homem que tenha a máxima de ajudar pessoas em necessidade e vê outro se afogando, se for um exímio nadador, se atira à água para salvá-lo. Se outra pessoa que tenha adotado a mesma máxima se vê diante de idêntica situação, mas não sabe nadar, gritará por socorro ou irá buscar quem possa auxiliar. As ações tomadas em ambos os casos foram mecanicamente diferentes, mas ambas foram aplicações concretas da mesma máxima ${ }^{29}$.

De igual modo, ações compostas dos mesmos movimentos exteriores podem possuir máximas muito distintas. Para saber se um ato de penetrar o abdômen de alguém com um facão é uma tentativa de homicídio ou uma intervenção médica, é preciso conhecer a máxima. É preciso conhecer a que se dirige a vontade do agente e a natureza do contexto em que se produz a ação.

Quer dizer, para Kant, o que dá inteligibilidade a uma ação humana é a sua máxima. É a máxima que permite definir a ação e também torná-la moralmente relevante. Em outras palavras, o que confere unidade a uma ação humana, ordenando o conjunto de movimentos mecânicos que a compõe e dando-lhe um sentido compreensível, é o princípio teleológico que

\footnotetext{
${ }^{28}$ Cf. id., ibid., pp. 29-32.

${ }^{29}$ Cf. HÖFFE, Otfried. Immanuel Kant. Trad. Christian Viktor Hamm, Valério Rohden. - São Paulo: Martins Fontes, 2005, pp. 203-206.
} 
dirige a vontade a um objeto da realidade. Portanto, a estrutura da ação humana é integralmente teleológica ${ }^{30}$.

O que caracteriza propriamente a ética e a diferencia do direito é exatamente o fato de que a ética julga as máximas das ações, enquanto o direito julga ações. Consequentemente, o tema da moralidade é sempre os fins e nunca simplesmente um ato considerado materialmente. Em Kant, não há "deveres frios" de fazer isto ou aquilo, independentemente de considerações circunstanciais, mas, ao contrário, uma lei que atua no interior da consciência, em seu ato interno de definir as diretrizes que orientam o nosso agir no dia-a-dia e as nossas vidas ${ }^{31}$.

O segundo corolário da centralidade da fórmula da humanidade, que, de certo modo, é uma continuação deste último, é que a própria ética, no sistema kantiano, é uma estrutura teleológica. A moral, no fundo, é uma adequação dos fins subjetivos de cada indivíduo aos fins objetivos que a razão mostra como necessários. O próprio Kant define a ética como "a doutrina dos fins da razão prática pura". Trata-se de outro modo de se diferenciar a ética do direito: enquanto o direito comanda externamente ações, que devem ser realizadas ou evitadas em seu aspecto fenomênico, independentemente dos princípios que guiam a consciência do agente, a moral comanda fins, ordena não ações em sentido material, mas as finalidades que devem orientar internamente a vontade ${ }^{32}$.

N'“A metafísica dos costumes", Kant defende que são dois os fins da razão que são também deveres de todo o ser racional: a própria perfeição e a felicidade alheia. A aspiração da razão prática pura, aquilo que a razão prática busca realizar (o bem completo), é a conjunção sintética entre a plena felicidade e a plena virtude moral. Portanto, a felicidade e a perfeição resumem o pendor natural da humanidade e a plena realização das potências racionais.

Evidentemente, por um lado, não pode ser um dever buscar a perfeição alheia porque está fora de nosso alcance até mesmo o conhecimento da virtude dos demais, que reside no íntimo de sua consciência e só em foro interno pode ser querida e buscada. Por outro, tampouco

\footnotetext{
${ }^{30}$ Cf. DE HARO ROMO, op. cit., pp. 35-36; 43-44.

${ }^{31}$ Cf. KANT. A metafísica dos costumes. Trad., textos adicionais e notas Edson Bini. - Bauru, SP: EDIPRO, $2^{\mathrm{a}}$ ed. rev., 2008, pp. 232-234.

${ }^{32}$ Cf. id., ibid., pp. 224-225.
} 
faz sentido chamar dever a própria felicidade já que todo o ser humano busca a felicidade por inclinação natural necessária. No âmbito empírico, o homem não pode não desejar a felicidade.

Desse modo, a própria perfeição e a felicidade alheia estruturam todo o sistema de fins e de deveres. Eles encarnam o fim primeiro e superior, o "fim em si mesmo", que é a própria humanidade (que não é outra coisa senão o imperativo categórico em si mesmo). A promoção da humanidade, a plena realização de todas as capacidades do ser racional, como fim último que dá sentido a todas as coisas, é o verdadeiro centro da ética kantiana ${ }^{33}$.

Com tudo o que foi exposto, percebemos claramente que, ao contrário do eu imagina a exposição tradicional, toda a estrutura interna da moralidade de Kant é teleológica. Não faz sentido pensar numa dicotomia rígida entre "deontologia versus teleologia". A deontologia kantiana não exclui o raciocínio teleológico, antes o supõe. A noção kantiana de dever em nada é avessa a bens e a fins.

Quando se compreende a ética kantiana dando-se primazia à fórmula da humanidade e não à formulação da universalização, pode-se observar que a ética em Kant não é um teste formal e vazio para a aprovação de máximas particulares e aleatórias, mas uma investigação acerca daquilo que convém à natureza humana. Também aqui Kant está mais próximo do projeto moral clássico do que se supõe, e esse ponto já nos abre a vereda para o último elemento que queremos explorar neste artigo.

\section{A MATERIALIDADE NA APLICAÇÃO DA ÉTICA KANTIANA}

O último aspecto do pensamento moral kantiano sobre o qual gostaríamos de nos debruçar nesta breve exposição são as obras de ética material. A maior parte dos estudiosos da ética de Kant se refere exclusivamente à "Fundamentação da metafísica dos costumes" e à "Crítica da razão prática". Tais obras, de fato, tratam da parte formal da moral, isto é, da explicitação conceitual dos fundamentos abstratos da ação e do juízo moral.

\footnotetext{
${ }^{33}$ Cf. id, ibid., pp. 229-231.
} 
Kant, porém, trata da aplicação da ética para a dedução dos deveres concretos n'“A metafísica dos costumes", sua obra da maturidade, e nas "Lições de ética"34, transcrições das aulas de Filosofia Moral que ministrou na Universidade de Königsberg ao longo de toda a sua carreira. Esses livros, amplamente ignorados pela literatura a respeito do filósofo alemão, são parte fundamental do edifício ético kantiano e são o culminar de suas reflexões, aquilo que mostra a ética atuando verdadeira no mundo e não apenas em conceitos abstratos. Kant mesmo afirma, no prefácio da "Fundamentação", que esse livro é uma propedêutica introdutória à "Metafísica dos costumes", a ser futuramente escrita ${ }^{35}$.

Quando se recorre à leitura de tais obras, simplesmente torna-se, agora em definitivo, impossível seguir sustentando a imagem de um Kant formalista e perdido em abstrações. Kant vai a todos os campos da vida e da ação humana, discute minúcias e exemplifica detalhes. Explica, por exemplo, por que é imoral mutilar-se ou amputar um abraço ${ }^{36}$ ou como devemos disciplinar nossos desejos e apetites corporais ${ }^{37}$.

Nesses escritos, vemos que a moral em Kant está muito longe de ser um amontoado de conceitos ideais, sem relação com a condição atual de cada pessoa. Kant é muito cuidadoso na tarefa de mostrar como as ideias morais se aplicam à realidade fenomênica e antropológica do mundo material onde os seres humanos vivem. Suas obras de ética material são justamente as responsáveis por essa passagem entre os fundamentos racionais da moralidade e a nossa condição próxima e concreta, experimentável no cotidiano ${ }^{38}$.

O pensamento de Kant conta com uma vigorosa antropologia subjacente. Ele próprio afirma, no início das "Lições de ética", que uma moral sem Antropologia é uma vã especulação ${ }^{39}$. Considerações antropológicas não podem ser o fundamento da lei moral (é o que Kant demonstra em suas obras mais conhecidas) uma vez que esta precisa valer universalmente, independentemente das circunstâncias fenomênicas do homem. Entretanto, a lei moral

\footnotetext{
${ }^{34}$ KANT. Lecciones de ética. Int. e notas Roberto Rodríguez Aramayo. Trad. Roberto Rodríguez Aramayo e Concha Roldán Panadero. Barcelona: Crítica, $3^{\mathrm{a}}$ ed., 2009.

${ }^{35}$ Cf. id., Fundamentação..., pp. 81-83.

${ }^{36}$ Cf. id., Lecciones..., pp. 187-188.

${ }^{37}$ Cf. id., ibid., pp. 198-199; 212-218.

${ }^{38}$ Cf. DE HARO ROMO, op. cit., pp. 69-70.

${ }^{39}$ Cf. KANT, op. cit., pp. 39-40.
} 
encontrada se aplica ao homem em sua natureza atual, e importa explicar como se dá essa interação na realidade da vida.

Kant não rechaça os sentimentos, nem os desconsidera como componentes importantes da humanidade. O que Kant diz na "Fundamentação" e na segunda "Crítica" é que simplesmente não podem ser o critério da moralidade. Não é possível identificar o que deve ser feito com aquilo que me faz sentir bem. Os sentimentos humanos são volúveis, variáveis e, muitas vezes, irracionais. O dever não pode depender deles. Qualquer um tem a experiência ordinária de um impulso em favor de uma satisfação instantânea, que contraria aquilo que sabe que deve fazer. Em muitos casos, a razão nos manda negar o que nos pedem os desejos sensíveis.

Kant reforça bastante esse ponto porque tem necessidade de opor-se aos utilitaristas e aos sentimentalistas britânicos, escolas que equiparavam a moralidade aos sentimentos. Isso não significa que os sentimentos sejam um elemento desprezível, a ser simplesmente dominado de modo tirânico por uma razão abstrata.

É falsa a noção de que Kant proponha um dualismo rigoroso, em que tudo o que existe no âmbito moral é uma lei formal e universal, que incide sobre cada uma das nossas ações. Assim, a cada ato, somos aprovados ou reprovados, sem matizes, sem nuances, sem possibilidades de vacilação e de redenção. Kant advoga uma luta constante por toda a vida, para superar nossas más inclinações. Vamos, pouco a pouco, com dificuldades e tropeços próprios de nossa constituição imperfeita, corrigindo nossos desejos e apetites que não estão, em algumas medidas, conformes com a razão e ordenando-os aos nossos fins necessários ${ }^{40}$.

Trata-se de um caminhar em direção à perfeição. Como comentamos anteriormente, a perfeição é um fim obrigatório da razão prática. A ética kantiana não mira, de modo algum, um "mínimo possível” para a convivência de pessoas de distintas ideias de bem, mas a perfeição do homem. A vida moral humana é uma luta constante, nesse caminhar permanente de aperfeiçoamento, em que vamos nos conformando cada dia mais às exigências da razão.

\footnotetext{
${ }^{40}$ Cf. VILLACAÑAS, José Luís. Kant. In: CAMPS, Victoria (ed.). Historia de la ética. II. La ética moderna. Barcelona: Crítica, 1992, pp. 394-396.
} 
Em tal caminhar, vamos sempre nos equilibrando numa tensão constante entre, por um lado, a consciência de nossa limitação e imperfeição e, por outro lado, nosso desejo de perfeição, que não nos permite perder o horizonte e a esperança que nos faz seguir caminhando retamente. Nessa luta por atingir a perfeição, segundo Kant (em passagem que chocaria a interpretação contemporânea), devemos contar sempre com o auxílio da graça divina, que supre a radical deficiência de nossa natureza ${ }^{41}$.

No estado de perfeição moral, os sentimentos acompanham a lei moral. O mais perfeito para o homem é que todas as suas faculdades estejam integradas numa unidade orgânica. Assim, se, em nosso estado fenomênico, é normal que nossos apetites estejam desordenados e, muitas vezes, se revelem contrários ao que vemos pela razão como melhor, quanto mais adquirimos a virtude, maior é a coincidência entre nossas faculdades sensíveis e nosso intelecto, e vamos também nos sentindo bem com aquilo que é verdadeiramente bom. Kant, por conseguinte, reproduz integralmente conhecida tese da tradição aristotélico-tomista ${ }^{42}$.

Kant tampouco é um inimigo da felicidade. A felicidade, ao contrário, tem um lugar de destaque na antropologia kantiana. Ela é definida como a plena e constante satisfação de todas as nossas inclinações sensíveis. Para Kant, esse é um desejo universal e necessário da natureza humana. Cada indivíduo terá um conteúdo diferente para a sua felicidade (consoante seus desejos, sua cultura e suas circunstâncias), mas todos os homens a desejam por aspiração inata $^{43}$.

A moralidade não só não ignora a felicidade, como Kant diz claramente que as exigências da razão não podem tornar impossível aquilo que é um desejo universal, integrante da própria constituição natural humana. A perfeição moral e a felicidade, se não podem ser reduzidas uma à outra, sempre caminham lado a lado como partes da plena realização humana ${ }^{44}$.

Kant, de fato, rejeita a felicidade como fundamento da ética. Isso porque, como acabamos de ver, sendo a felicidade o conjunto estável de nossas satisfações empíricas, seu

\footnotetext{
${ }^{41}$ Cf. KANT, op. cit., p. 48.

${ }^{42}$ Cf. id., ibid., pp. 83-85.

${ }^{43}$ Cf. Id., Crítica da razão prática..., p. 38.

${ }^{44}$ Cf. id., ibid., pp. 98-106.
} 
conteúdo concreto varia de pessoa para pessoa, não servindo como pilar para normas universalmente válidas.

Tal tese do iluminista prussiano não está, como pode parecer à primeira vista, em franca oposição a Aristóteles. A felicidade, em Kant, é um conceito estritamente empírico, referindose à satisfação de nossos apetites sensíveis. A felicidade aristotélica, por sua vez, não é uma noção empírica, mas normativa ${ }^{45}$. O que Kant chama de felicidade não é a eudaimonia aristotélica. O próprio Kant o reconhece, em passagem das "Lições de ética", na qual constata que a eudaimonia dos antigos não corresponde ao que ele nomeia como felicidade em seu sistema, mas ao seu conceito de sumo bem (que é a plena realização humana, a conjunção entre a absoluta virtude e a absoluta felicidade ${ }^{46}$.

Se lermos simultaneamente o início do primeiro livro da "Ética a Nicômaco"47 e as primeiras linhas da "Fundamentação" 48 , encontraremos um belíssimo paralelo. Tanto Aristóteles quanto Kant iniciam sua investigação moral pelo mesmo raciocínio: é preciso encontrar o fundamento último da ética, e este só pode estar naquilo que é bom por si mesmo. As coisas que são boas para alguma finalidade externa a si extraem sua bondade de um bem superior. É preciso buscar o bem universal, aquilo que não é bom para nada fora de si, mas que tem valor intrínseco e, portanto, é a fonte do todo o valor moral.

Aristóteles descobre tal objeto na felicidade (eudaimonia) e Kant na boa vontade. Entretanto, como agora insistimos, a felicidade aristotélica, de modo algum, é alheia ao raciocínio kantiano. A eudaimonia é, no sistema kantiano, sumo bem, o bem humano completo (a união permanente entre a perfeição moral e a plena satisfação). E o sumo bem é a meta da boa vontade, aquilo que a razão prática pura buscar realizar no mundo, a aspiração necessária e natural da razão.

Em suma, podemos observar que ambas as formulações morais são sutilmente diferentes, mas guardam muito mais semelhanças do que se costuma supor. Em Aristóteles, a

\footnotetext{
${ }^{45}$ Cf. VIGO, Alejandro G. Aristóteles y Kant, em torno al origen de la cualidad moral de la acción. In: Id., Conciencia, ética y derecho: estúdios sobre la filosofia práctica de Kant, Santiago: IES, 2020 (no prelo), pp. 139140.

${ }^{46}$ Cf. KANT, Lecciones de ética..., pp. 43-44.

${ }^{47}$ Cf. ARISTÓTELES, Ética a Nicômaco. Trad., texts. ads. e notas Edson Bini. - São Paulo: EDIPRO, 2014, pp. 43 e ss.

${ }^{48}$ Cf. KANT, Fundamentação..., pp. 101 e ss.
} 
felicidade é o fundamento da bondade moral, enquanto, em Kant, o fundamento é a boa vontade, mas a aspiração próprio da boa vontade, aquilo que ela busca realizar no âmbito prático, é a felicidade aristotélica.

Concluímos aqui estas breves notas, que pretendem resumir, no exíguo espaço deste trabalho, os elementos centrais de uma interpretação da ética kantiana contrária à leitura formalista mais habitual. Apoiamo-nos nos próprios textos de Kant e em diversos comentadores que vêm se esforçando por defender essa interpretação, talvez para muitos ainda tida por novidade. É meu desejo que também em nosso meio acadêmico esse debate, já muito presente em diversos fóruns do mundo, seja levantado e que a representação mais manualizada e vulgarizada de Kant seja submetida à adequada crítica, necessária ao amadurecimento das ideias.

\section{CONCLUSÃO}

Como advertido desde o início, os temas trazidos à colação neste artigo (todos centrais ao pensamento moral tanto de Kant quanto de Aristóteles) necessitariam de muitos livros para que fossem desenvolvidos integralmente. $\mathrm{O}$ objetivo do presente texto não foi mais do que apresentar um panorama geral dos elementos frequentemente ignorados da ética kantiana que fundamentam uma interpretação bastante contrária a que normalmente é oferecida.

Consoante revelam as referências bibliográficas aqui aportadas, muitos são os textos de Kant que precisam de uma leitura mais cuidadosa, apta a eventualmente trazer à lume a leitura que aqui propomos (particularmente, seus livros de ética material, os mais comumente ignorados dentro do sistema da filosofia prática kantiana - "A metafísica dos costumes" e as "Lições de ética"). Igualmente, tivemos a oportunidade de citar diversos importantes comentadores do pensador alemão que vêm desenvolvendo esta interpretação, como Otfried Höffe, Terence Irwin, Allen Wood, Karl Ameriks, Vicente de Haro Romo.

Creio que os três pontos em que dividimos o desenvolvimento do presente texto representam bem os elementos centrais que caracterizam a visão mais tradicional da moralidade 
kantiana e do abismo paradigmático que a separa das éticas clássicas. Buscamos aqui atacar os principais rótulos normalmente aplicados para construir esse esquema dual que opõe Aristóteles e Kant em dois mundos incomensuráveis.

Primeiro, a leitura construtivista que, desde a consagração de Rawls como o principal filósofo político do século passado, adquiriu enorme importância nos debates acerca de Kant. Tentamos mostrar que, do ponto de vista do estatuto metafísico da lei moral, não há fundamento na obra de Kant para classificá-lo como um "construtivista". A lei moral é um fato, o factum da razão, um dado numênico da realidade inteligível. A moral não é uma produção humana, mas a ordenação própria dos seres racionais, que integra sua natureza e aponta para o seu ideal inato de perfeição. Kant é um realista, ao estilo dos moralistas clássicos.

Segundo, a oposição entre a ética deontológica kantiana e as éticas teleológicas antigas (que fundamenta todo um dualismo radical entre o mundo moral dos antigos, povoado de "fins", de "bens", de "natureza", de "felicidade", e o dos modernos, recheado de "leis" e de "deveres"). Buscamos trazer evidências para sustentar que a deontologia kantiana não só não é avessa a uma teleologia, mas como antes a pressupõe. Toda a estrutura, tanto descritiva quanto normativa, da ação humana em Kant é teleológica, e o próprio dever é formulado teleologicamente (o imperativo categórico é a pedra de toque de um sistema que articula e hierarquiza finalidades, conforme expresso pela formulação da humanidade).

Terceiro, por fim, o formalismo, ou procedimentalismo, muitas vezes associado ao kantismo, que seria proponente de uma ética modestamente resumida a um teste lógico vazio para aprovar planos subjetivos e ideias pessoais. Pusemos sob luz os textos em que Kant realiza a tarefa de aplicar concretamente a filosofia moral (em minha opinião, os textos verdadeiramente centrais de sua teoria ética), diante dos quais se faz muito difícil insistir na imagem de um pensador rigorista lógico. Kant possui uma explicação longa e detalhada de cada um dos deveres concretos que compõe a integralidade da normativa da vida humana, além de mostrar como a ética se incorpora à vida humana real, a partir da integração de uma cuidadosa antropologia. Aí, vemos como Kant entende a moralidade como um projeto de vida, de uma luta constante pelo autoaperfeiçoamento, e não como a incidência fria e cruel de uma lei ideal e abstrata, que esmaga e censura nossas vacilações com uma exigência impiedosa. 
Vimos, ainda, que tanto os sentimentos, quanto a felicidade têm um lugar na estrutura moral kantiana e que seu ideal de perfeição da natureza humana culmina (como objeto necessariamente buscado pela razão prática pura) com a eudaimonia aristotélica. Assim, podese defender que nenhum dos motivos que normalmente se invocam para encarar Kant como um adversário mortal de Aristóteles, de fato, acaba por manter-se de pé. Kant é um realista, sua ética é de estrutura teleológica e profundamente substancial.

Como já dito, em muitos fóruns do debate acadêmico sobre a compreensão de Kant, esta visão ora esposada vem sendo defendida contra a representação mais consagrada dos manuais. Este brevíssimo artigo não tem outra pretensão que a de trazer uma pequena contribuição, para a melhor divulgação de tal interpretação e do embate teórico dela recorrente, a fim de, quem sabe, instigar novas descobertas que podem ser feitas com olhares sempre novos sobre os clássicos da teoria moral.

\section{REFERÊNCIAS BIBLIOGRÁFICAS}

AMERIKS, Karl. Interpreting Kant's Critiques. Oxford: Oxford University Press, 2003.

ANSCOMBE, G. E. M.. Modern Moral Philosophy. In: The Collected Philosophical Papers of G. E. M. Anscombe, vol. III: Ethics, Religion and Politcs, Oxford: Basil Blackwell, 1981.

ARISTÓTELES, Ética a Nicômaco. Trad., texts. ads. e notas Edson Bini. - São Paulo: EDIPRO, 2014.

BROAD, C. D.. Five Types of Ethical Theory. Londron: Routledge \& Kegan Paul, 1930.

DE HARO ROMO, Vicente. Duty, Virtue and Practical Reason in Kant's Metaphysics of Morals. Trad. Erik Norvelle. Hildesheim/Zurich/New York, OLMS, 2015.

ENGSTROM, Stephen e WHITING, Jennifer (eds.). Aristotle, Kant, and the Stoics: Rethinking Happiness and Duty. Cambridge: Cambridge University Press, 1996.

FRANKENA, William. Ethics. 2a ed. Englewood Cliffs: Prentice Hall, 1973.

HÖFFE, Otfried. Immanuel Kant. Trad. Christian Viktor Hamm, Valério Rohden. - São Paulo: Martins Fontes, 2005. 
KANT, Immanuel. A metafísica dos costumes. Trad., textos adicionais e notas Edson Bini. Bauru, SP: EDIPRO, 2a ed. rev., 2008.

Crítica da razão prática. Trad., int. e notas Valerio Rohden. - São Paulo: Editora WMF Martins Fontes, $3^{\mathrm{a}}$ ed., 2011.

Fundamentação da metafísica dos costumes. Trad., int. e notas Guido Antônio de Almeida. - São Paulo: Discurso Editorial: Barcarolla, 2009.

Lecciones de ética. Int. e notas Roberto Rodríguez Aramayo. Trad. Roberto Rodríguez Aramayo e Concha Roldán Panadero. Barcelona: Crítica, 3ª ed., 2009.

MACINTYRE, Alasdair. Depois da virtude: um estudo em teoria moral. Trad. Jussara Simões, rev. téc. Hélder Buenos Aires de Carvalho. - Bauru, SP: Edusc, 2001.

RAWLS, John. Collected Papers. Ed. Samuel Freeman. Cambridge: Harvard University Press, 1999.

História da filosofia moral. Org. Barbara Herman, trad. Ana Aguiar Cotrim, rev. da trad. Marcelo Brandão Cipolla. - São Paulo, Martins Fontes, 2005.

Uma teoria da justiça. Trad. Jussara Simões, rev. téc. Álvaro de Vita. - $3^{\text {a }}$ ed.

- São Paulo: Martins Fontes, 2008.

ROSS, David. The Right and the Good. Ed. rev., ed. Phillip Stratton-Lake, Oxford: Clarendon Press, 2002.

SIDGWICK, Henry. Outlines of the History of Ethics for English Readers. London: Macmillan and Co., $6^{\mathrm{a}}$ ed., 1931.

VIGO, Alejandro G. Aristóteles y Kant, em torno al origen de la cualidad moral de la acción. In: Id., Conciencia, ética y derecho: estúdios sobre la filosofia práctica de Kant, Santiago: IES, 2020 (no prelo).

VILLACAÑAS, José Luís. Kant. In: CAMPS, Victoria (ed.). Historia de la ética. II. La ética moderna. Barcelona: Crítica, 1992.

WOOD, Allen W. Kant. Trad. Delamar José Volpato Dutra. - Porto Alegre: Artmed, 2008.

Data de Submissão: 16/11/2020

Data de Aceite: $30 / 11 / 2020$ 